\title{
Polymorphism of 1,3-X-adamantanes $\left(\mathrm{X}=\mathrm{Br}, \mathrm{OH}, \mathrm{CH}_{3}\right)$ and the crystal plastic phase formation ability
}

\author{
Philippe Negrier, ${ }^{a}$ Bacem Ben Hassine, ${ }^{a, b}$ Maria Barrio ${ }^{b}$, Michela Romanini ${ }^{b}$, Denise Mondieig and \\ Josep-Lluis Tamarit ${ }^{\mathrm{b}, *}$
}

\begin{abstract}
The polymorphism of 1,3-dimethyladamantane (13DMA), 1,3-adamantanediol (13DOHA) and 1,3-dibromoadamantane (13DBrA) has been studied by $X$-ray powder diffraction, density measurements and differential scanning calorimetry at normal and high-pressure. 13DMA displays a low-temperature ordered monoclinic phase (space group $P 2_{1} / c, Z=4, Z^{\prime}=1$ ) which transforms at $222.6 \pm 0.5 \mathrm{~K}$ to a high-temperature hexagonal plastic phase $\left(P G_{3} / m m c, Z=26\right.$, stable up to the melting point at $246.8 \pm 0.5 \mathrm{~K}$ at normal pressure. $13 \mathrm{DOHA}$ displays a low-temperature hexagonal phase $\left(P 6_{3} / \mathrm{mcm}, \mathrm{Z}=6, \mathrm{Z}^{\prime}=0.25\right)$ which transforms to a face-centered cubic plastic phase $(F m \overline{3} m)$. 13DBrA exhibits a unique ordered orthorhombic phase (Pnma, Z=4, Z'=0.5) which remains till the melting point at $382.1 \pm 0.5 \mathrm{~K}$. The stability temperature domain of the plastic phases increases with pressure for both 13DMA and 13DOHA. The ability to form plastic phase for these compounds as well as a series of adamantanes derivatives is analysed through the globularity and asphericity parameters derived from the Hirshfeld surface analysis
\end{abstract}

\section{INTRODUCTION}

Rational design efforts to build up new crystalline molecular materials require the understanding and control of intermolecular interactions in the solid state. To achieve such goal, crystal engineering [1] i.e., the ability to predict and control, or even to predict crystal structures, has attracted much attention over the last decades, in particular in the field of the construction of crystalline supramolecular architectures for functional materials with technological and biomedical applications. [2-5]

One of the most successful supramolecular architectures is the building blocks known as diamondoids. They are of great interest thanks to their important role in supramolecular chemistry and material sciences with applications in broad areas as nanotechnology, [6] biotechnology, [7] organic surface functionalization, [8] building up organic crystals with large cavities and useful physical and chemical properties, [9-11] and pharmaceutical and related applications. [12-14]

In particular, 1,3-dicarbonyl adamantanes are specially interesting for the synthesis of biological active compounds or chemically stable polymers among other chemical compounds of industrial interest, $[15,16]$ despite the starting raw material is usually the 1,3adamantanecarboxilic acid with a limited availability. To avoid such disadvantage, processes have been improved by using 1,3dimethyladamantane. [17] A synthesis process using 1,3 dibromoadamantane in absence of solvent has been described for the ligand 1,3-bis(1,2,4-triazol-1-yl)adamantane, which is interesting for its coordination chemistry. [18] Adamantane oxygenates as 1,3adamantanediol are as well precursors for the production of photoresists, medicines, and supramolecular polymeric materials. $[19,20]$.

The cornerstone of the diamondoids group is the adamantane molecule, $\mathrm{C}_{10} \mathrm{H}_{16}$, a rigid molecule with point group symmetry $T_{d}$ formed by 10 carbon atoms arranged as a single diamond cage surrounded by 16 hydrogen atoms. [21] The adamantane affords one of the best known examples of an organic molecular crystal which undergoes an order-disorder phase transition, with a hightemperature phase in which molecules are orientationally disordered (plastic phase). [22]
Simple substituted at either 1- (tertiary carbon) or 2- (secondary carbon) positions of adamantane show a rich polymorphic behaviour that has largely been characterized. [23-33] Many, but not all, of these substituted compounds display a plastic phase. Moreover, the existence of a hydrogen bonding scheme is not a condition to preclude orientational disorder [23, 34-37]. Within this concern, Hulme et al. [38] suggested that the existence of orientational disorder, i.e., the existence of a plastic crystal phase, can be hindered by specific intermolecular interactions such as hydrogen bonding. Nevertheless, it has been demonstrated that for more or less "globular shaped molecules", such an interaction cannot prevent the plastic crystal forming ability [23,34-37]. Thus, the ability to display such a disordered phase is still a matter of debate and a clear balance between intermolecular interactions and globular shape of the molecular entities is still unknown. $[39,40]$

In the present study we report on solid state structures and on the thermodynamic phase behaviour of compounds obtained from adamantane by replacing two of the $\mathrm{H}$ atoms attached to the 1 - and 3-three-coordinated (tertiary) carbons by methyl $\left(\mathrm{CH}_{3}\right)$ groups, 1,3dimethyladamantane (13DMA), Br atoms 1,3-dibromoadamantane (13DBrA) and hydroxyl groups (OH), 1,3-adamantanediol (13DOHA). Its plastic phase formation ability is discussed by compiling a series of adamantane derivatives.

\section{EXPERIMENTAL DETAILS}

Materials. The three substances were purchased from Sigma Aldrich with purity of $99 \%+$.

Differential thermal analysis at normal pressure. Thermal analysis measurements at normal pressure were conducted by means of a Q100 thermal analyser from TA Instruments equipped with a RCS low-temperature device. Heating and cooling rates of $2 \mathrm{~K} \cdot \mathrm{min}^{-1}$ under a constant nitrogen stream were used. Sample masses of ca. $4 \mathrm{mg}$ were weighed by means of a $0.01 \mathrm{mg}$ sensitive balance.

High-pressure measurements. High-pressure differential thermal analysis (HP-DTA) measurements were carried out at a $2 \mathrm{~K} \cdot \mathrm{min}^{-1}$ heating rate by means of an in-house built high-pressure differential thermal analyser similar to Würflinger's apparatus. [41] Temperature 
and pressure ranges were between 200 and $473 \mathrm{~K}$ and 0 and 300 $\mathrm{MPa}$, respectively. Samples were sealed in cylindrical tin pans by melting the studied substance taking care that in-pan volumes were free of air.

Additional high-pressure measurements within the pressure range 300-500 MPa were performed for 13DMA by means of a highpressure dielectric cell. A cylindrical stainless-steel capacitor was covered with a Teflon membrane and latex wrapping to avoid contamination with the pressurizing liquid (Huber oil). The capacitor was placed into a $\mathrm{Cu}$-Be high-pressure chamber. Temperature scans at constant pressure were performed to determine the solid-solid transition temperature through the change of the dielectric permittivity across the transition. Details of the experimental system can be found in ref. [42].

X-ray powder diffraction measurements. X-ray powder diffraction data were recorded by means of a horizontally mounted INEL cylindrical position-sensitive detector (CPS120) equipped with a liquid nitrogen 700 series Cryostream Cooler from Oxford Cryosystems with a temperature accuracy of $0.1 \mathrm{~K}$ and similar for fluctuations. The detector, used in Debye-Scherrer geometry, consisted of 4096 channels, providing an angular step of $0.029^{\circ}(2 \theta)$ between 2 and $120^{\circ}$. Monochromatic $\mathrm{Cu} \mathrm{K} \alpha_{1}$ radiation ( $\lambda=1.54056 \AA$ ) was selected with an asymmetric focusing incident-beam curved quartz monochromator. The conversion channel-angle was performed by means of cubic spline fittings in order to correct the deviation from angular linearity in position-sensitive detector (PSD) according to recommendations using the cubic phase $\mathrm{Na}_{2} \mathrm{Ca}_{3} \mathrm{Al}_{2} \mathrm{~F}_{14}$ mixed with silver behenate [43-44] as external-calibration. Samples were introduced into 0.5 - $\mathrm{mm}$-diameter Lindemann capillaries which rotate along their longitudinal axes during data collection to minimize the effects of the preferred orientations.

$\mathrm{X}$-Ray patterns were acquired isothermally between $90 \mathrm{~K}$ and the melting point for 13DMA and 13DOHA, and till $486 \mathrm{~K}$ for 13DBrA in order to determine the lattice parameters as a function of temperature as well as the volume variation at the first order phase transitions.

Acquisition times were at least $60 \mathrm{~min}$, and a stabilization time of at least $5 \mathrm{~min}$ at each temperature before data acquisition was selected. Longer time acquisition patterns were obtained at some temperatures for structural and refinement purposes.

The structure of the low-temperature ordered phases were determined by means of long acquisition time high-resolution $\mathrm{X}$-ray powder diffraction patterns. X-cell software [45] was used to index the lattices and a Pawley profile-fitting procedure minimizing the $\mathrm{R}$ factor $\left(R_{\text {wp }}\right)[46]$ to confirm the space group as well as to refine the unit cell parameters, the zero-shift, the background and peak profile (pseudo-Voigt) parameters.

To fully determine the structure, rigid body molecules were built up by replacing the two hydrogens attached to the tertiary carbons in the adamantane molecule by two methyl groups for 13DMA, two $\mathrm{Br}$ atoms for 13DBrA and two $\mathrm{OH}$ groups for 13DOHA.

Molecular energy minimization with the Forcite module (energy minimization using Dreiding forcefield) [47] has been used for the molecular parameters. For the final structural solution, molecules were placed in a general position randomly oriented and through the Powder Solve [48] (Monte-Carlo approach), both position and orientation of molecules within the unit lattice were refined. For a fine tuning of all structural data, Rietveld [49] refinements were conducted alternatively with energy minimization within the rigidbody constraint, a single overall isotropic displacement parameter and a preferred orientation by using the Rietveld-Toraya function. [50] The used software is included in MS Modelling from Materials Studio. [51]
Density Measurements. Liquid density measurements at normal pressure were carried out for 13DMA from 278 to $335 \mathrm{~K}$ using an Anton Paar D5000 densitometer with temperature stability of $0.02 \mathrm{~K}$ and uncertainties in density of ca. $5 \cdot 10^{-5} \mathrm{~g} \mathrm{~cm}^{-3}$. The densitometer was calibrated with literature data of bidistilled water and $n$-hexane (99.9\%). [52,53]

\section{RESULTS AND DISCUSSION}

Thermodynamic results. Thermodynamic data at the solid-solid and melting transitions determined by means of DSC at normal pressure are summarized in Table 1.

Both 13DMA and 13DOHA exhibit solid-solid phase transitions (II-I) in addition to the melting process (I-L). As for the melting process, entropy changes were found to be $(0.72 \pm 0.04) R$ and $(2.2 \pm 0.2) R$, respectively, lower than the quoted value from Timmermans for the melting of orientationally disordered (plastic) phases (2.5R), thus supporting the orientationally disordered character of phase I (vide infra).[56] On the contrary, 13DBrA exhibits only the solid-liquid phase transition in the $90-390 \mathrm{~K}$ range (melting temperature at $382.1 \pm 0.3 \mathrm{~K})$, with an entropy change of $(3.37 \pm 0.04) \mathrm{R}$, in agreement with the Timmermans' criterion (i.e., higher than 2.5R). It should be noticed that related mono-brominated adamantane derivatives, as 1-bromoadamantane ( $\mathrm{C}_{3 \mathrm{v}}$ molecular symmetry) [33] and 2bromoadamantane ( $C_{s}$ molecular symmetry) [24], do present a plastic phase before melting.

The pressure-dependence of the solid-solid phase transitions and the melting process are shown in Figure 1.

The Clausius-Clapeyron equation:

$$
\frac{d T}{d p}=\frac{\Delta v}{\Delta s}
$$

provides the volume variation $(\Delta v)$ at the first-order phase transition by using experimental values of the entropy change $(\Delta s=\Delta h / T)$ and the slope $\mathrm{d} T / \mathrm{d} p$. Values of $\Delta v$ from X-ray diffraction measurements and calculated through eq.(1) are reported in Table 1.
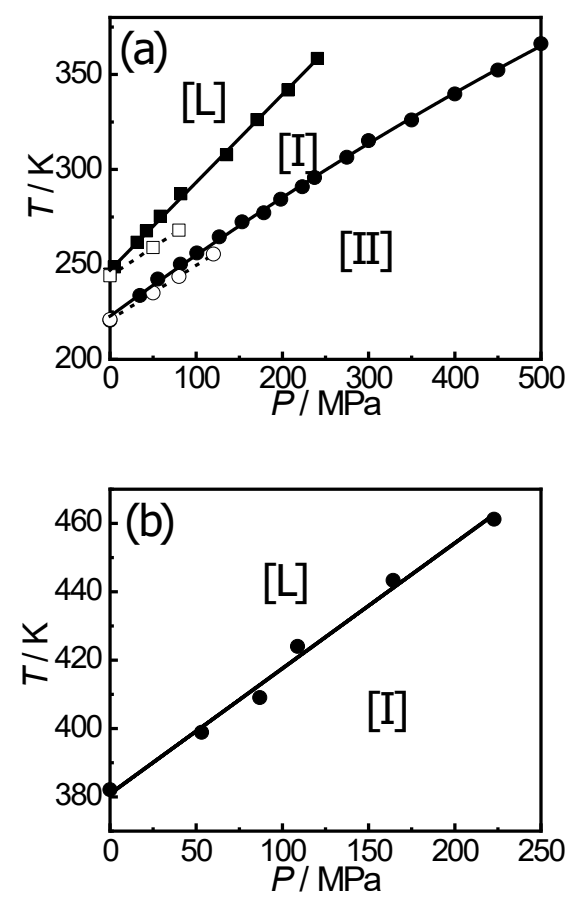


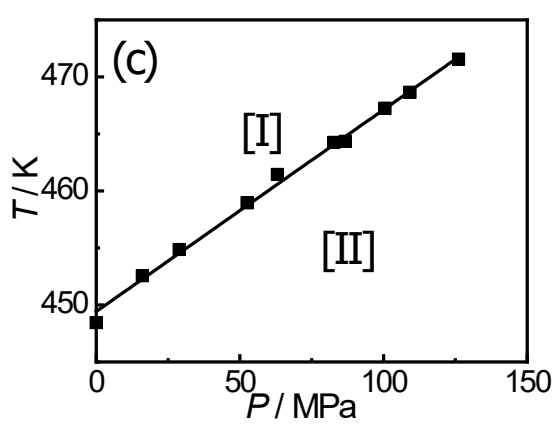

Figure 1. Pressure-temperature phase diagrams for (a) 13DMA: $T_{\mid I-I}=(-$ 9.3.10-5 $\left.\pm 1.5 \cdot 10^{-5}\right) \cdot \mathrm{p}^{2}(\mathrm{MPa})^{2}+(0.331 \pm 0.007) \cdot \mathrm{p}(\mathrm{MPa})+(222.7 \pm 0.8) \mathrm{K}$ for the II to I transition and $\mathrm{T}_{\mathrm{I}-\mathrm{L}}(\mathrm{K})=(0.4625 \pm 0.0057) \cdot \mathrm{p}(\mathrm{MPa})+(247.0 \pm 0.7)$ $\mathrm{K}$ for the I to $\mathrm{L}$ transition. (b) $13 \mathrm{DBrA}: \mathrm{T}_{\mathrm{I}-\mathrm{L}}(\mathrm{K})=(0.366 \pm 0.016) \cdot \mathrm{p}(\mathrm{MPa})$ $+(380.9 \pm 2.2) \quad$ K. $\quad$ (c) $13 \mathrm{DOHA}: \mathrm{T}_{\mathrm{III}-\mathrm{I}}(\mathrm{K})=(0.177 \pm 0.004) \cdot \mathrm{p}(\mathrm{MPa})+$ (449.4 \pm 0.3$)$. Empty symbols for $13 \mathrm{DMA}$ in a) are the corresponding values obtained from ref. [57].

\section{Crystallographic results}

According to the procedure described in the experimental section, the final refined patterns of the low-temperature phases for the three compounds are depicted in Figure $\mathbf{2}$. Table $\mathbf{2}$ gathers the main refined parameters after the convergence of the procedure.

Lattice parameters as a function of temperature were determined from $90 \mathrm{~K}$ up to the melting (for $13 \mathrm{DBrA}$ ) and to the order-disorder phase transition (for 13DMA and 13DOHA). Values are gathered in the Supplementary Information (Tables S1, S3 and S4). In addition, Pawley refinement of patterns collected as a function of temperature for the plastic phases of 13DMA and 13DOHA were performed (see Supplementary Information, Tables S2 and S5, and Figure S1). These measurements enable to determine the volume as a function of temperature for the involved crystalline phases and thus the volume changes at the transition temperatures (see Supplementary Information, Figures S2, S3). As for the 13DMA, density values of the liquid phase enabled to determine $\Delta v$ at the melting process (see Table 1).
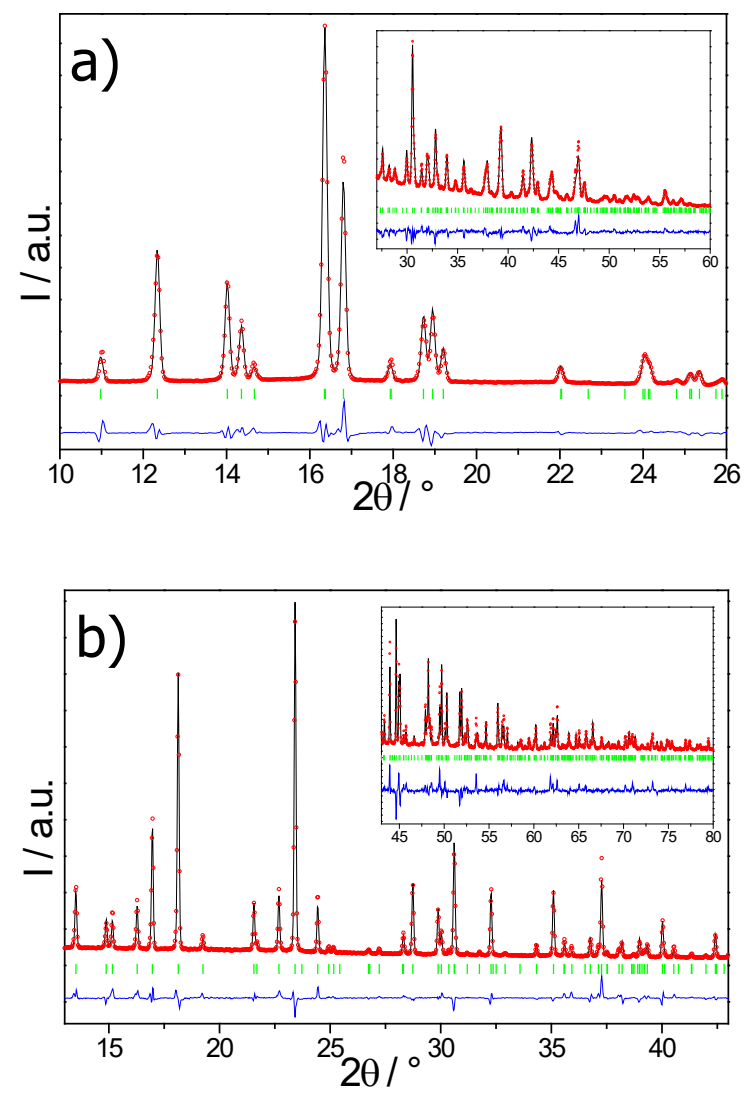

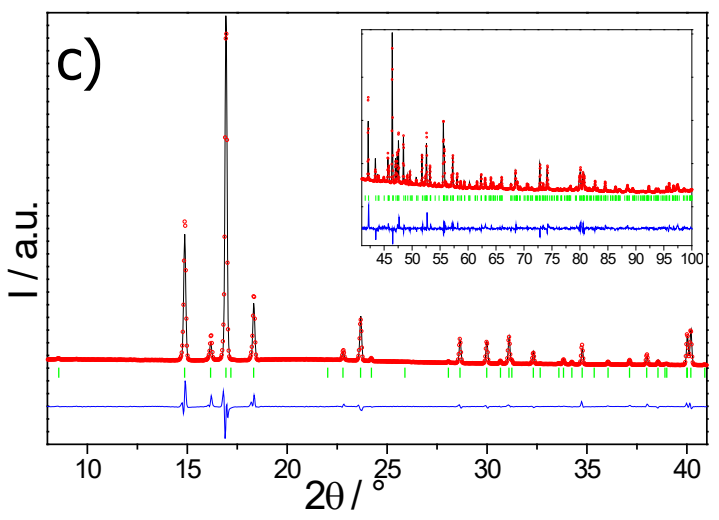

Figure 2 Experimental (red circles) and Rietveld refined (black line) diffraction patterns along with difference profile (blue line) and Bragg reflections (vertical sticks) of the monoclinic $P 2_{1} / c$ space group phase II of 1,3-dimethyladamantane at $120 \mathrm{~K}$ (a), orthorhombic Pnma phase I of 1,3-dibromoadamantane at $294 \mathrm{~K}$ (b) and hexagonal $P 6_{3} / \mathrm{mcm}$ phase I of 1,3-adamantanediol at $294 \mathrm{~K}$ (c). Insets correspond to the scale magnified 10 times for a), 7 times for $b$ ) and 17 times for $\mathrm{c}$ ) respectively to enhance visibility.
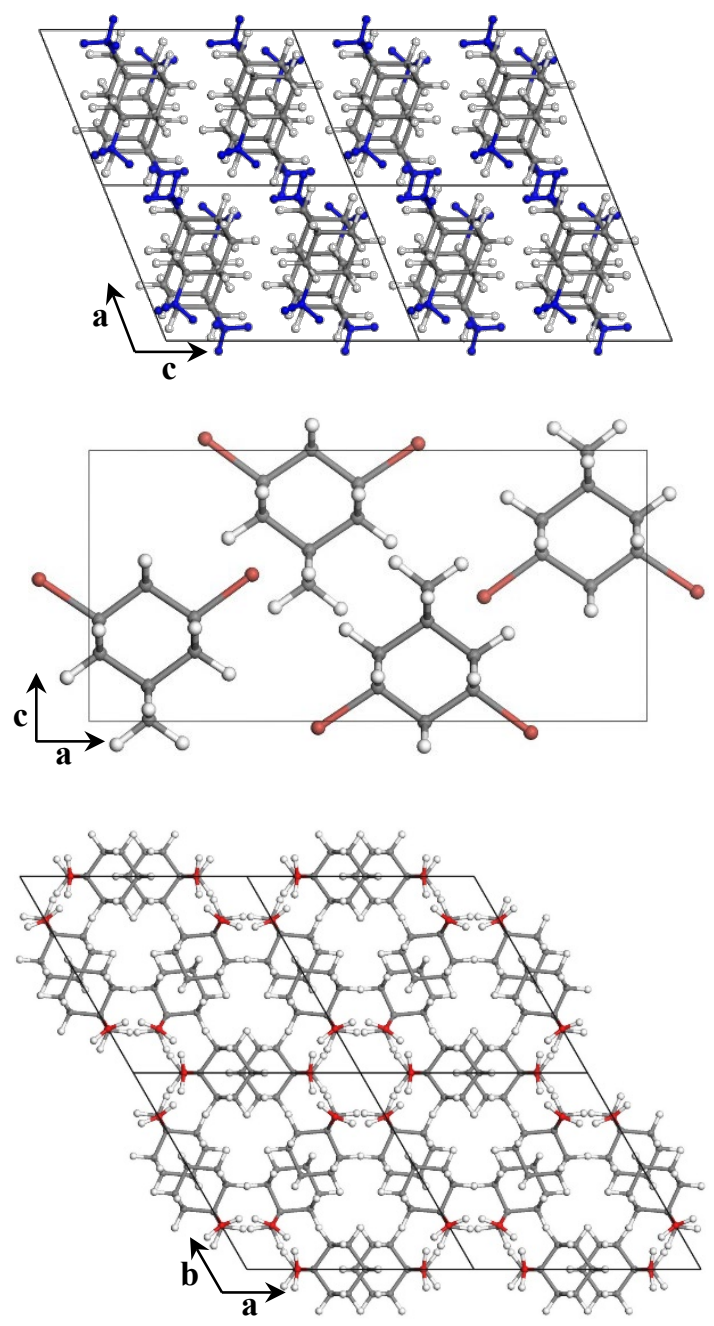

Figure 3. Top panel: Projection along $b$ of the crystal structure of the low-temperature phase $\|\left(P Z_{1} / c, \quad Z=4, Z^{\prime}=1\right)$ of 1,3dimethyladamantane (13DMA) at $120 \mathrm{~K}$. The methyl groups are colored in blue. Central panel: Projection along $\mathrm{b}$ of the crystal 
structure of phase I of 1,3-dibromoadamantane (13DBrA) (Pnma $\left.Z=4, Z^{\prime}=0.5\right)$ at $294 \mathrm{~K}$. Bottom panel: Projection along $\mathrm{c}$ of the crystal structure of phase $\|\left(P 6_{3} / \mathrm{mcm}, Z=6\right)$ of 1,3-adamantanediol (13DOHA) at $294 \mathrm{~K}$.

\section{Discussion}

The structure of the 13DMA is shown in Figure 3a within the $a-c$ plane. The weak interactions between methyl groups (highlighted in blue in Figure 3a) are localized in the $b$-c plane, with the shortest intermolecular distances $\mathrm{H} \cdots \mathrm{H}$ between nearest methyl groups of 2.46(4) $\AA$, while 2.170(6) $\AA$ is found for the shortest $\mathrm{H} \cdots \mathrm{H}$ distances between nearest 13DMA molecules.

The relatively large distance between methyl groups causes a lowdensity structure of phase II of 13DMA (see Supplementary Information Figure S2). The density measurements, carried out at normal pressure in the liquid state, give rise to an extrapolated density at the melting point of $\mathrm{D}_{\mathrm{L}}(\mathrm{T}=246.8 \mathrm{~K})=0.934 \mathrm{~g} \cdot \mathrm{cm}^{-3}$. According to the volume changes determined from the thermodynamic data (see Table 1) and, in particular, through the Clausius-Clapeyron eq.(1), density values of phase I at the II-I and I-L transition temperatures ( 222.6 and $246.8 \mathrm{~K}$, respectively) of 0.976 and $0.955 \mathrm{~g} . \mathrm{cm}^{-3}$ were found. Both values are compatible with a number of molecules of $Z=26$ for the disordered phase I (so then, $\left.V / Z=169.1 \mathrm{~cm}^{3} \cdot \mathrm{mol}^{-1}\right)$.

The Pawley fitting procedure of patterns for phase I of 13DMA (see Figure $S 1$ in Supplementary Information) provide the $P G_{3} / m m c$ space group with lattice parameters of $a=b=25.281(12) \AA$ and $c=13.108(6)$ $\AA$ at $220 \mathrm{~K}$.

The structure of the ordered phase I of 13DBrA was determined as orthorhombic (space group Pnma). The molecules have their C-Br bonds situated on the mirror perpendicular to the $\boldsymbol{b}$ axis so that the asymmetric unit is composed of a half molecule $\left(Z^{\prime}=0.5\right)$ and the unit cell contains only four molecules. As a consequence, the refinement of the molecule position allows only a rotation around the $\boldsymbol{b}$ axis and two translations along $\boldsymbol{a}$ and $\boldsymbol{c}$ axes. The $a-c$ plane of the ordered structure, depicted in Figure $\mathbf{3}$ (central panel), evidences that the resulting dipole of the two $\mathrm{C}-\mathrm{Br}$ dipoles is nearly parallel to the $\boldsymbol{c}$ axis with an angle of $2.7^{\circ}$. The crystal cohesion is produced by van der Waals and $\mathrm{Br} \cdots \mathrm{Br}$ interactions $(\mathrm{Br} 1 \cdots \mathrm{Br} 2=3.630$ (3) $\AA$ ). The shortest $\mathrm{Br} \cdots \mathrm{H}$ distance is $3.087(2) \AA$ which is higher to the sum of van der Waals radii. The values of the angles $\theta_{1}=\mathrm{C} 1-\mathrm{Br} 1 \cdots \mathrm{Br} 2$ and $\theta_{2}=\mathrm{C} 3-$ $\mathrm{Br} 2 \cdots \mathrm{Br} 1$ are close, $155.8^{\circ}$ and $153.2^{\circ}$, respectively. It has been reported that there are two preferred geometries for halogen $\cdots$ halogen contacts, for the first one $\theta_{1}=\theta_{2}$ and for the second one $\theta_{1} \approx 180^{\circ}$ and $\theta \approx 90^{\circ}$. [58]. So, the geometry of halogen $\cdots$ halogen interaction can be classified as type one. It may be noticed that these halogen ...halogen contacts are not present in the mono substituted 1-bromoadamantane. [25,33]

As for 13DOHA, the structure of the low-temperature ordered hexagonal phase II displays a $P \sigma_{3} / \mathrm{mcm}(Z=6)$ space group, with $a=b=11.9118(6) \AA, c=10.9590$ (7) $\AA$ at $294 \mathrm{~K}$ ). The molecules are localized on the two $a-b$ and $a-c$ mirrors given rise to a structure of high symmetry with $Z^{\prime}=0.25$. As a consequence, the hydrogen atom linked to the oxygen lies on two symmetrical positions with an equal fractional occupancy of $50 \%$. Three kinds of hydrogen bond configuration in adamantanes have been reported: dimer as for 1adamantanecarboxylic acid [59], tetramer as for 1-adamantanol [60] and hexamer as for 1-adamantane-methanol [23]. For 13DOHA, as for the 1-adamantane-methanol [23], the hydrogen bonds involve the $\mathrm{O}-\mathrm{H}$ dipoles of six neighbouring molecules in a three-dimensional hydrogen bonding hexagonal network (see Figure 3, bottom panel) which is perpendicular to the $c$ axis. The intermolecular $0 \cdots O$ and
$\mathrm{H} \cdots \mathrm{O}$ distances are $2.741(2) \AA$ and $1.796(2) \AA$, respectively, and the angle $\mathrm{O}-\mathrm{H} \cdots \mathrm{O}$ is $165.80(3)^{\circ}$. These values are similar to those of the low-temperature (monoclinic $P 2_{1} / n$ ) phase of 1 -adamantanemethanol with similar hydrogen bonding scheme [23]. The hightemperature phase I of 13DOHA is orientationally disordered $(F m \overline{3} m)$, with a $=9.9891(17) \AA$ at $479.8 \mathrm{~K}$. Lattice parameters obtained from Pawley refinement (Figure S1) and volume as a function of temperature are given in Supplementary Information (see Table S2). It is worth mentioning that despite 13DOHA displays an extensive hydrogen bonding network in the low-temperature phase, it transforms to an orientationally disordered high-temperature phase, while 1-adamantane-methanol, with quite similar hydrogen bonding network does not.

Worth recalling here is that the relative volume change at the transition, $\frac{V_{I}}{V_{I I}}=1.08-1.07$, is higher than that at the melting [61-70] ( $\frac{V_{L}}{V_{I}} \approx 1.01$ for 13DMA for example) the former being much closer to the value obtained for many organic systems at the melting process, $\frac{v_{L}}{v_{s}}=1.10 \pm 0.07 .[71,72]$ Such result confirms the preponderance of the orientational degrees of freedom, which for plastic crystals "melt" at the solid-solid (II-I) phase transition instead of at the melting process (I to L). [70,73]

In addition, it must be mentioned that both the volume change at the melting and the slope of the two-phase coexistence curve, $\left(\frac{d T}{d P}\right)_{I-L^{\prime}}$, are close to the volume change at the ordered to orientationally disordered transition for some adamantane derivatives. [24-25, 59]

From the experimental pressure-temperature phase diagrams of 13DMA and 13DOHA, it becomes clear that increasing pressure gives rise to an increase of the temperature domain of the plastic phase I (see Figure 1), as is usually observed for the studied plastic crystal materials so far. $[62,64,69]$ This means that the ratio between the II to $I$ and I to Liquid temperatures, $T_{\mid I-I} / T_{I-L}$, continuously decreases when increasing pressure. Such a behavior has been explained as due to a faster increase of the reorientational energy barrier than the energy barrier for diffusion according to the theory of Amzel and Becka, [74] which is an extension of the theory of fusion by LennardJones and Devonshire theory. The extended theory nicely provides the splitting of the melting of a full ordered solid phase into two processes: a solid to orientationally disordered phase transition and the final melting of the orientationally disordered phase. Thus, when increasing pressure, diffusion of molecules would require more space, unlike the orientational diffusion. This is a straightforward consequence of the existence of only van der Waals interactions between molecules. This goes along the small values of the activation energy for reorientational motions determined from IR and Raman spectroscopy (13.0 kJ.mol-1 for 13DMA [75], for example) This energy barrier to rotation is similar to other adamantane derivatives governed by "soft" van der Waals interactions, as 1-F-adamantane $\left(13.3 \mathrm{~kJ}^{\mathrm{mol}}{ }^{-1}\right)$ [24] or 2-adamantanone (12.5 kJ.mol-1) [76], and much lower than that in which halogen-halogen interactions play a dominant role, as for $1-\mathrm{Br}$-adamantane $\left(35.6 \mathrm{~kJ} . \mathrm{mol}^{-1}\right)$ and $1-\mathrm{Cl}-$ adamantane $\left(27.5 \mathrm{~kJ} \cdot \mathrm{mol}^{-1}\right)$. [77]

Despite the arguments claimed to explain the plastic phase formation ability, clear criteria remain still elusive. The seminal works of Timmermans [56] pointed out the globular nearly spherical shape of molecules as the main criterion for the existence of a plastic phase, without considering the intermolecular interactions. To quantify the 
aforementioned criterion, two parameters have recently been proposed as a tool, the globularity and the asphericity, both available from the Hirshfeld surface analysis [78] of the low-temperature ordered structures of the concerned materials. From the volume and the surface area of the Hirshfeld molecular surface, globularity is calculated as the ratio of the surface area of a sphere of equal total volume to the Hirshfeld surface area. Asphericity, which represents the molecular anisotropy, is determined as the relation between the principal inertia moments of the Hirshfeld surface and those of the sphere (thus, 0 for a sphere and 1 for a disk).

Table 3 gathers globularity and asphericity parameters obtained from the volume and surface area of the Hirshfeld analysis for the 1,3-Xadamantanes studied in this work together with those for 1- and 2-Xadamantane derivatives for which low-temperature structures have been found in the literature. For the sake of reference, values for the adamantane parent material has been also calculated. Details of the Hirshfeld calculations are provided in the Supplementary Information (Figures S4 to S6).
Figure 4 evidences that globularity for adamantane derivatives is high when compared to compounds previously reported which exhibit a plastic phase $[39,40,80]$. Similarly, the asphericity parameter for the aforementioned compounds is quite small. It is worth noting that, overall, the decrease (increase) of the globularity (asphericity) increases the stability domain of the plastic phase (here quantified as the ratio between the solid to plastic phase transition temperature and the melting temperature). Altogether, it does mean that, as a general rule, adamantane derivatives are clear examples of compounds exhibiting plastic phases. Nevertheless, Figure 4 clearly evidences that neither the globularity nor the asphericity are the key parameters to predict the formation of the plastic phase. Speaking examples are $13 \mathrm{DBrA}$ and $1 \mathrm{MOA}$, both displaying globularity and asphericity parameters within the same range as the materials considered here, but without a high-temperature plastic phase.

Table 1: Transition temperatures $(T)$, enthalpy $(\Delta H)$ and entropy changes $(\Delta S)$ derived from DTA measurements and volume changes determined from X-ray powder diffraction measurements $\left(\Delta v^{\times R}\right)$ and from the slope of the pressure-temperature two-phase equilibria $\left(d T_{c} / d p\right)^{\exp }$ derived from the application of the Clausius-Clapeyron equation $\left(d T_{c} / d p\right)^{c C}$ at normal pressure $\left(\Delta v^{H P}\right)$ for 1,3-dimethyladamantane $\left(\mathrm{C}_{12} \mathrm{H}_{20}\right), 1$,3-dibromoadamantane $\left(\mathrm{C}_{10} \mathrm{H}_{14} \mathrm{Br}_{2}\right)$ and 1,3-adamantanediol $\left(\mathrm{C}_{10} \mathrm{H}_{16} \mathrm{O}_{2}\right)$.

${ }^{\text {a }}$ From ref [33] ${ }^{\mathrm{b}}$ From ref [55] ${ }^{\mathrm{c}}$ From ref [54]

\begin{tabular}{|c|c|c|c|c|c|}
\hline \multirow[b]{2}{*}{ Property } & \multicolumn{2}{|c|}{$\begin{array}{l}\text { 13DMA } \\
\left(\mathrm{C}_{12} \mathrm{H}_{20}\right)\end{array}$} & \multirow{2}{*}{$\begin{array}{c}\text { 13DBrA } \\
\left(\mathrm{C}_{10} \mathrm{H}_{14} \mathrm{Br}_{2}\right) \\
\text { I(Pnma) to L }\end{array}$} & \multicolumn{2}{|c|}{$\begin{array}{c}13 \mathrm{DOH} \\
\left(\mathrm{C}_{10} \mathrm{H}_{16} \mathrm{O}_{2}\right)\end{array}$} \\
\hline & $\begin{array}{l}\|\left(P 2_{1} / \mathrm{c}\right) \text { to } \\
\text { I(P6 } / \mathrm{mmc})\end{array}$ & $\mathrm{I}\left(\mathrm{P} 6_{3} / \mathrm{mmc}\right)$ to $\mathrm{L}$ & & $\begin{array}{l}\|\left(\mathrm{PG}_{3} / \mathrm{mcm}\right) \text { to } \\
(\mathrm{Fm} \overline{3} \mathrm{~m})\end{array}$ & $\mathrm{I}(\mathrm{Fm} \overline{3} \mathrm{~m})$ to $\mathrm{L}$ \\
\hline$T / \mathrm{K}$ & $\begin{array}{c}222.6 \pm 0.5 \\
221^{\mathrm{a}} \\
221^{\mathrm{b}} \\
221.38 \pm 0.01^{\mathrm{c}}\end{array}$ & $\begin{array}{c}246.8 \pm 0.5 \\
245^{a} \\
244^{b} \\
247.79 \pm 0.01^{c} \\
243^{b}\end{array}$ & $382.1 \pm 0.3$ & $450.3 \pm 0.5$ & $588.9 \pm 0.5$ \\
\hline $\begin{array}{c}\Delta H \\
/ \mathrm{kJ} \cdot \mathrm{mol}^{-1}\end{array}$ & $\begin{array}{c}9.3 \pm 0.4 \\
7.36 \pm 0.36^{\mathrm{a}} \\
7.65^{\mathrm{b}} \\
9.31 \pm 0.01^{\mathrm{c}}\end{array}$ & $\begin{array}{c}1.47 \pm 0.07 \\
0.92 \pm 0.01^{\mathrm{a}} \\
0.94^{\mathrm{b}} \\
1.541 \pm 0.004^{\mathrm{c}}\end{array}$ & $10.7 \pm 0.9$ & $26 \pm 2$ & $11 \pm 1$ \\
\hline $\begin{array}{c}\Delta S \\
/ \mathrm{J} \cdot \mathrm{mol}^{-1} \cdot \mathrm{K}^{-1}\end{array}$ & $\begin{array}{c}41.8 \pm 1.9 \\
33.31^{\mathrm{a}} \\
34.6^{\mathrm{b}} \\
41.66 \pm 0.06^{\mathrm{c}} \\
\end{array}$ & $\begin{array}{c}6.0 \pm 0.3 \\
3.76^{\mathrm{a}} \\
3.85^{\mathrm{b}} \\
6.22 \pm 0.02^{\mathrm{c}} \\
\end{array}$ & $28.0 \pm 2.4$ & $58 \pm 5$ & $19 \pm 2$ \\
\hline$\Delta v^{\mathrm{XR}}(\mathrm{p}=0.1 \mathrm{MPa}) / \mathrm{cm}^{3} \cdot \mathrm{mol}^{-1}$ & $11.4 \pm 0.3$ & $3.4 \pm 0.5$ & & $10.8 \pm 0.8$ & \\
\hline$\Delta v^{\mathrm{HP}}(\mathrm{p}=0.1 \mathrm{MPa}) / \mathrm{cm}^{3} \cdot \mathrm{mol}^{-1}$ & $13.8 \pm 0.9$ & $2.80 \pm 0.17$ & $10.2 \pm 1.4$ & $10.3 \pm 3.2$ & \\
\hline$(\mathrm{dT} / \mathrm{dp})^{\exp } / \mathrm{K} \cdot \mathrm{MPa}^{-1}$ & $0.331 \pm 0.007$ & $0.462 \pm 0.006$ & $0.366 \pm 0.016$ & $0.177 \pm 0.004$ & \\
\hline
\end{tabular}

Table 2: Results from the Rietveld refinement for the solid phases of 1,3-dimethyladamantane (13DMA, $\mathrm{C}_{12} \mathrm{H}_{20}$ ), 1,3-dibromoadamantane (13DBrA, $\mathrm{C}_{10} \mathrm{H}_{14} \mathrm{Br}_{2}$ ) and 1 ,3adamantanediol (13DOHA, $\mathrm{C}_{10} \mathrm{H}_{16} \mathrm{O}_{2}$ ).

\begin{tabular}{cccc}
\hline Phase & Phase II & Phase I & Phase II \\
\hline Abbreviation & $13 \mathrm{DMA}$ & $13 \mathrm{DBrA}$ & $13 \mathrm{DOHA}$ \\
Formula & $\left(\mathrm{C}_{12} \mathrm{H}_{20}\right)$ & $\left(\mathrm{C}_{10} \mathrm{H}_{14} \mathrm{Br}_{2}\right)$ & $\left(\mathrm{C}_{10} \mathrm{H}_{16} \mathrm{O}_{2}\right)$ \\
\hline $\mathrm{FW}\left(\mathrm{g} \cdot \mathrm{mol}^{-1}\right)$ & 164.28 & 294.03 & 168.23 \\
\hline Crystal system & Monoclinic & Orthorhombic & Hexagonal \\
\hline Space group & $\mathrm{P} 2_{1} / \mathrm{c}$ & Pnma & $\mathrm{P} 6_{3} / \mathrm{mcm}$ \\
\hline $\mathrm{T}(\mathrm{K})$ & $120(1)$ & $294(1)$ & $294(1)$ \\
\hline Wavelength $(\AA)$ & 1.54056 & 1.54056 & 1.54056 \\
\hline \multirow{2}{*}{ Unit cell dimensions } & $a=7.7576(18) \AA$ & $14.9792(9) \AA$ & $11.9118(6) \AA$ \\
\cline { 2 - 4 } & $b=12.085(2) \AA$ & $9.7677(6) \AA$ & $11.9118(6) \AA$ \\
\hline & $c=11.707(2) \AA$ & $7.2734(5) \AA$ & $10.9590(7) \AA$ \\
\hline
\end{tabular}




\begin{tabular}{cccc}
\hline & $\gamma=90^{\circ}$ & $90^{\circ}$ & $120^{\circ}$ \\
\hline$Z\left(Z^{\prime}\right)$ & $4(1)$ & $4(0.5)$ & $6(0.25)$ \\
\hline$V\left(\AA^{3}\right)$ & $1015.7(3)$ & $1064.19(12)$ & $1346.66(13)$ \\
\hline$D_{x}\left(g^{-c m}\right)^{-3}$ & 1.074 & 1.833 & 1.245 \\
\hline$\left.R_{\text {wp }} \%\right)$ & 6.62 & 7.36 & 7.67 \\
\hline$\left.R_{p} \%\right)$ & 4.50 & 5.07 & 4.71 \\
\hline
\end{tabular}
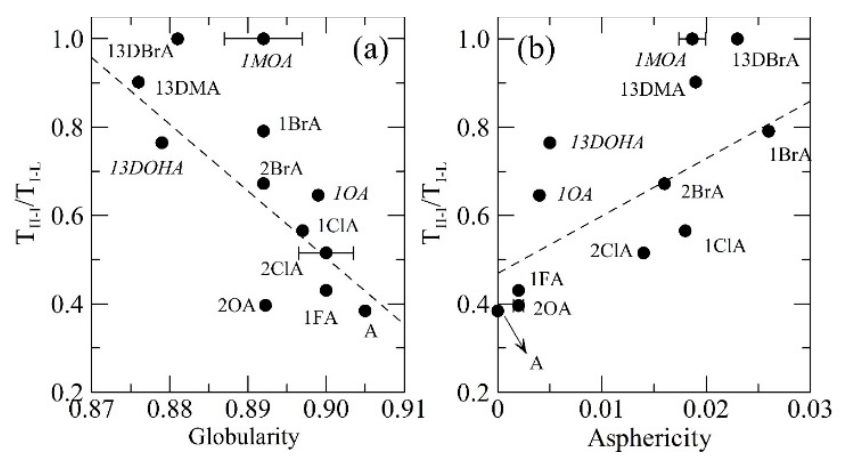

Figure 4. Ratio between the solid to plastic phase transition temperatures $\left(T_{I I-1}\right)$ and the melting temperatures $\left(T_{1-L}\right)$ for some adamantane derivatives gathered in Table $\mathbf{3}$ as a function of the globularity (a) and asphericity (b) parameters as derived from the Hirshfeld analysis of the low-temperature phases (II).

\section{Conclusions}

The polymorphism of 1,3-dimethyladamantane, 1,3dibromoadamantane and 1,3-adamantanediol has been studied from $90 \mathrm{~K}$ to the liquid state.

As far 1,3-dimethyladamantane, the low-temperature phase II, which was found to be monoclinic with space group $P 2_{1} / c(Z=4)$ transforms to the high-temperature orientationally disordered hexagonal (space group $P 6_{3} / m m c, Z=26$ ) phase I. The stability of these phases was studied as a function of pressure and no additional phase appears due to the increase in pressure within the studied range (500 $\mathrm{MPa})$. The stability of the ordered phase II increases with pressure, whereas orientationally disordered phase is much more stabilized with respect to the liquid phase.

As far 1,3-dibromoadamantane, only one ordered orthorhombic (Pnma, Z=4, $Z^{\prime}=0.5$ ) phase with a melting point at normal pressure of $382 \mathrm{~K}$ and till pressure of $225 \mathrm{MPa}$ appears. This phase is characterized by halogen...halogen interactions through dipoledipole interactions.

Despite the hydrogen bonded scheme displayed by 1,3adamatanediol, a high-temperature plastic phase appears. The lowtemperature phase is hexagonal $\left(P 6_{3} / \mathrm{mcm}, Z=6, Z^{\prime}=0.25\right)$ and exhibits a statistical disorder of the hydrogen atom linked to the oxygen atom, due to the position of the molecules on the two mirrors. The high temperature phase $(F m \overline{3} m)$ is orientationally disordered. From the Hirshfeld surface analysis of the lowtemperature ordered phases of the three 1,3-X-adamantane derivatives as well as $1-X-$ and 2 -X-adamantane derivatives whose structures were previously reported, it is concluded that neither the globularity nor the asphericity parameters can be used to predict the plastic crystal phase formation ability.

Table 3. Hirshfeld surface volume (V), surface area (A), globularity $(G)$ and asphericity $(A)$, solid to plastic phase transition temperatures $\left(T_{11-1}\right)$ and melting temperatures ( $\left.T_{1-L}\right)$, and ratio between them $\left(T_{1-1 / 1} / T_{-1-1}\right)$ at normal pressure for some adamantane derivatives (short name identifies the compound in Figure 4). For compounds without plastic phase, the nonexisting solid to plastic phase transition temperature is considered equal to the melting temperature. Short names in italic indicate the existence of the hydrogen bonds in the lowtemperature ordered phase. \# Values of $\mathrm{V}$ and $\mathrm{A}$ of the Hirshfeld analysis were calculated for the 3 different configurations due to the presence of 3 independent molecules within the low-temperature monoclinic phase (see ref.23). The values in parenthesis report on the limiting values of the calculations for those configurations.

\begin{tabular}{|c|c|c|c|c|c|c|c|c|}
\hline Compound & $\begin{array}{l}\text { Short } \\
\text { Name }\end{array}$ & $\mathrm{V} / \AA^{3}$ & $\mathrm{~A} / \AA^{2}$ & G & A & $\mathrm{T}_{\text {III-I}} / \mathrm{K}$ & $\mathrm{T}_{\mathrm{ILL}} / \mathrm{K}$ & $T_{1 \mid-1} / T_{1-L}$ \\
\hline 1,3-dibromoadamantane & 13DBrA & 260.75 & 224.15 & 0.881 & 0.023 & 382.1 & 382.1 & 1 \\
\hline 1,3-dimethyladamantane & 13DMA & 249.27 & 218.77 & 0.876 & 0.019 & 222.6 & 246.8 & 0.902 \\
\hline 1,3-adamantanediol & $13 D O H A$ & 219.55 & 200.25 & 0.879 & 0.005 & 450.3 & 588.9 & 0.765 \\
\hline 2-bromoadamantane $\mathrm{e}^{25}$ & $2 \mathrm{BrA}$ & 224.06 & 200.11 & 0.892 & 0.016 & 277.9 & 413.4 & 0.672 \\
\hline 2-chloroadamantane ${ }^{25}$ & $2 \mathrm{ClA}$ & 217.97 & 194.64 & 0.900 & 0.014 & 240.9 & 467.5 & 0.515 \\
\hline 2-adamantanone ${ }^{76}$ & $20 A$ & 194.68 & 181.98 & 0.893 & 0.003 & 221.0 & 557.5 & 0.396 \\
\hline 1-fluoroadamantane ${ }^{24}$ & $1 \mathrm{FA}$ & 198.42 & 182.71 & 0.9 & 0.002 & 226 & 525 & 0.430 \\
\hline 1-adamantane-methanol ${ }^{23, \#}$ & $1 M O A$ & $\begin{array}{l}239.6 \\
(1.2)\end{array}$ & $\begin{array}{c}209.1 \\
(1.1)\end{array}$ & $\begin{array}{c}0.892 \\
(0.008)\end{array}$ & $\begin{array}{c}0.0187 \\
(0.0015)\end{array}$ & 389.5 & 389.5 & 1 \\
\hline 1-chloroadamantane ${ }^{28}$ & $1 \mathrm{ClA}$ & 220.23 & 196.7 & 0.897 & 0.018 & 248.6 & 439.7 & 0.565 \\
\hline 1-bromoadamantane ${ }^{33}$ & $1 \mathrm{BrA}$ & 225.72 & 200.93 & 0.892 & 0.026 & 309.9 & 391.8 & 0.791 \\
\hline 1-adamantano| ${ }^{60}$ & $10 A$ & 211.33 & 190.83 & 0.899 & 0.004 & 357.1 & 552.9 & 0.646 \\
\hline Adamantane $^{79}$ & $A$ & 192.3 & 178.03 & 0.905 & 0 & 208.6 & 543.2 & 0.384 \\
\hline
\end{tabular}

There are no conflicts to declare.

\section{Conflicts of interest}




\section{Acknowledgements}

This work has been partially supported by the Spanish Ministry of Science and Innovation through project FIS2017-82625-P and by the Generalitat de Catalunya under project 2017SGR0042.

\section{Notes and references}

[1] G. R. Desiraju, Crystal Engineering. The Design of Organic Solids, Elsevier, Amsterdam, (1989).

[2] Z. Tang, Y.P. Wang, N.A. Kotov, Adv. Mater., 2006,18, 3203-3224.

[3] N. Schultheiss, A. Newman, Cryst. Growth Des., 2009, 9, 29502967.

[4] N. Blagden, M. de Matas, P.T. Gavan, P. York, Adv. Drug Delivery. 2007, 59, 617-630.

[5] E. Coronado, J.R. Galan-Mascaros, C.J. Gomez-Garcia, V. Laukhin, Nature, 2000, 408, 447-449.

[6] Y.S. Park, A. K. Cook, H. Wang, Nano Lett., 2006. 6, 2075-2079.

[7] L. Bacakova, E. Filova, M. Parizek, T. Ruml, V. Svorcik, Biotech. Adv., 2011, 29, 739-767.

[8] J.V. Barth, G. Costantini, K. Kern, Nature, 2005, 437, 671-679.

[9] A. Yamamoto, S. Uehara, T. Hamada, M- Miyata, I. Hisake, N. Tohnai, Cryst. Growth Des. 2012, 12, 4600-4606.

[10] M. A. Gunawan, J. C. Hierso, D. Poinsot, A. A. Fokin, N. A. Fokina, B.A Tkachenko, P. R. Schreiner, New J. Chem., 2014, 38, 28-41.

[11] M. J. Zaworotko, Chem. Soc. Reviews., 1994, 23, 283-288.

[12] Y.Y. Wang, E. Kiopakis, X.H. Lu, D. Wegner, R. Yamachika, J. E. Dahl, R. M. K. Carlson, S. G. Louie, M. F. Crommie, Nature Mater., 2008, 7, 38-42.

[13] W. L. Yang, J. D. Fabbri, T. M. Willey, J. R. I. Lee, J. E. Dahl, R. M. K. Carlson, P. R. Schreiner, A. A. Fokin, B. A. Tkachenko, N. A. Fokina, W. Meevasana, N. Mannella, K. Tanaka, X. J. Zhou, T. van Buuren, M. A. Kelly, Z. Hussain, N. A. Melosh, Z. -X. Shen, Science, 2007, 316, 1460-1462.

[14] K. G. Nicholson, J. M. Wood, M. Zambon, Lancet, 2003, 362, 1733-1745.

[15] J. Zhang, S. Chen, R. Nieto, T. Wu, P. Feng, X. Bu, Angew. Chem., Int. Ed., 2010, 49, 1267-1270.

[16] S. H. Chen, J. C. Mastrangelo, H. Shi, A. Bashir-Hashemi, J. Li, N. Gelber, Macromolecules, 1995, 28, 7775-7778.

[17] I. S. Akhrem, D. V. Avetisyan, L. V. Afanaseva, Tetrahedron Letters, 2012, 53, 3493-3496.

[18] R. Marchenko; A. Potapov; MolBank. 2017, 4, M968.

[19] N. Ishito, H. Kobayashi, K. Nakajima, Y. Maegawa, S. Inagaki, K. Hara, A. Fukuoka, Chem. A Eur. J., 2015, 21, 15564-15569.

[20] E. A. Ivleva, I. A. Platonov, Y. N. Klimochkin, Russ. J. Gen. Chem., 2015, 85, 1830-1833.

[21] V. Vijayakumar, A.B. Garg, B.K. Godwal, S.K. Sikka, Chem. Phys. Lett., 2000, 330, 275-280.

[22] H. Suga, S. Seki, J. Non-Cryst. Solids, 1974, 16, 171-194.

[23] B. Ben Hassine, Ph. Negrier, M. Barrio, D. Mondieig, S. Massip, J. LI. Tamarit, Cryst. Growth Des. 2015, 15, 4149-4155.

[24] B. Ben Hassine, Ph. Negrier, M. Romanini, M. Barrio, R. Macovez, A. Kallel, D. Mondieig, J. LI. Tamarit, Phys. Chem. Chem. Phys., 2016, 18, 10924-10930.

[25] Ph. Negrier, M. Barrio, D. Mondieig, J. LI. Tamarit, J. Phys. Chem. B., 2014, 118, 9595-9603.

[26] Ph. Negrier, M. Barrio, M. Romanini, J. LI. Tamarit, D. Mondieig, A. I. Krivchikov, L. Kepinski, A. Jezowski, D. Szewczyk, Cryst. Growth Des., 2014, 14, 2626-2632.

[27] R. Decressain, J. P. Amoureux, L. Carpentier, J. B. Nagy, Mol. Phys.,1991, 73, 553-569.
[28] M. Foulon, T. Belgrand, C. Gors, M. More, Acta Crystallogr. B, 1989, 45, 404-411.

[29] F. Affouard, A. Hedoux, Y. Guinet, T. Denicourt, M. Descamps, J. Phys. Condens. Matter., 2001, 13, 7237-7248.

[30] J. P. Amoureux, J. L. Sauvajol, M. Bee, Acta Crystallogr. A., 1981, 37, 97-104.

[31] J. P. Amoureux, M. Bee, J. L. Sauvajol, Acta Cryst. B 1982, 38,1984-1989.

[32] M. Bee, J. P. Amoureux, Mol. Phys., 1983, 48, 63-79.

[33] R. Betz, P. Klüfers, P. Mayer, Acta Crystallogr. E., 2009, 65,101.

[34] J. Salud, D. O. López, M. Barrio, J. LI. Tamarit, H. A. J. Oonk, Y. Haget and P. Negrier, J. Solid State Chem., 1997, 133, 536-544.

[35] J.LI.Tamarit, M.A.Pérez-Jubindo and M.R.de la Fuente, J. Phys. Condens. Matter, 1997, 9, 5469-5478.

[36] M. Barrio, D. O. López, J. Ll. Tamarit, P. Negrier, Y. Haget, J. Solid State Chem., 1996, 124, 29-38.

[37] M. Barrio, D. O. López, J. Ll.Tamarit, P. Negrier and Y. Haget, J. Mater. Chem., 1995, 5, 431-439.

[38] A. T. Hulme, A. Johnston, A. J. Florence, P. Fernandes, K. Shankland, C. T. Bedford, G. W. A. Welch, G. Sadiq, D. A. Haynes, W. D. S. Motherwell, D. A. Tocher, S. L. Price, J. Am. Chem. Soc., 2007, 129, 3649-3657.

[39] S. V. S. Bebiano, M.T.S. Rosado. R.A.E. Castro, M. Ramos Silva, J. Canotilho, T. M. R. Maria, M. E. S. Eusébio, J. Mol. Struct., 2019, 18,10-19

[40] T. M. R. Maria, M. T. S. Rosado, M. F. Oliveira, S. S. Bebiano, R. A. E. Castro, E. Juszyńska-Gałązka, M. Ramos Silva, J. Canotilho, M. E. S. Eusébio, CrystEngComm, 2019, 21, 3395-3408

[41] A. Würflinger, Phys. Chem. Chem. Phys., 1975, 79, 1195-1201.

[42] M. Romanini, M. Barrio, S. Capaccioli, R. Macovez, M. D. RuizMartin, J. LI. Tamarit, J. Phys. Chem. C, 2016, 120, 10614-10621.

[43] J. Ballon, V. Comparat, J. Pouxe, Instrum. Methods, 1983, 217, 213-216.

[44] M. Evain, P. Deniard, A. Jouanneaux, R. Brec, J. Appl. Crystallogr., 1993, 26, 563-569.

[45] M. A. Neumann, J. Appl. Crystallogr., 2003, 36, 356-365.

[46] G. S. Pawley, J. Appl. Crystallogr., 1981, 14, 357-361.

[47] S. L. Mayo, B. D. Olafson, W. A. Goddard, J. Phys. Chem., 1990, 94, 8897-8909.

[48] G. E. Engel, S. Wilke, O. König, K. D. M. Harris, F. J. J. Leusen, J. Appl. Crystallogr,, 1999, 32, 1169-1179.

[49] H. M. Rietveld, J. Appl. Crystallogr., 1969, 2, 65-71.

[50] H. Toraya, F. Marumo, Mineral. J., 1981, 10, 211-221.

[51] MS Modeling (Materials Studio), version 5.5: http://accelrys.com/products/collaborative science/bioviamaterials-studio/.

[52] S. L. Randzio, J.-P. E. Grolier, J. R. Quint, D. J. Eatough, E. A. Lewis, L. D. Hansen, Int. J. Thermophys., 1994, 15, 415-441.

[53] F. I. Mopsik, J. Res. Nat. Bur. Stand. Sec. A, 1967, 71, 287-292.

[54] R.M. Varushchenko, A.I. Druzhinina, V.M. Senyavin, V.S. Sarkisova, J. Chem. Thermodynamics, 2005, 37, 141-151.

[55] A. Scheider, R. W. Warren, E. J. Janovski, J. Am. Chem. Soc., 1964, 86, 5365-5367

[56] J. Timmermans, J. Phys. Chem. Solids, 1961, 18, 1-8.

[57] H. Arntz, G. M. Schneider, Faraday Discussion, 1980, 69, 139145.

[58] F. F. Awwadi, R. D. Willett, K. A. Peterson and B. Twamley, Chem. Eur. J., 2006, 12, 8952-8960.

[59] E. O. R. Beake, M. G. Tucker, M. T. Dove, A. E. Phillips, Chem. Phys. Chem., 2017 18, 459-464.

[60] J. P. Amoureux, M. Bee, C. Gors, V. Warin, F. Baert, Cryst. Struct. Comm., 1979, 8, 449-454.

[61] J. LI. Tamarit, M. Barrio, L. C. Pardo, Ph. Negrier, D. Mondieig, J. Phys. Condens. Matter., 2008, 20, 244110. 
[62] J. Reuter, D. Büsing, J. LI. Tamarit, A. Würflinger, J. Mater. Chem., 1997, 7, 41-46.

[63] Ph. Negrier, M. Barrio, J. LI. Tamarit, N. Veglio, D. Mondieig, Cryst. Growth Des., 2010, 10, 2793-2800

[64] M. Jenau, J. Reuter, J. LI. Tamarit, A. Würflinger, J. Chem. Soc., Faraday Trans., 1996, 92, 1899-1904.

[65] R. Levit, M. Barrio, N. Veglio, J. LI. Tamarit, Ph. Negrier, L. C. Pardo, J. Sanchez-Marcos, D. Mondieig, J. Phys. Chem. B, 2008, 112, 13916-13922.

[66] M. Barrio, J. LI. Tamarit, Ph. Negrier, L. C. Pardo, N. Veglio, D. Mondieig, New J. Chem., 2008. 32, 232-239.

[67] J. LI. Tamarit, D. O. López, X. Alcobé, M. Barrio, J. Salud, L. C. Pardo, Chem. Mater., 2000, 12, 555-563.

[68] P. Negrier, L. C. Pardo, J. Salud, J. LI. Tamarit, M. Barrio, D. O. López, A. Würflinger, D. Mondieig, Chem. Mater., 2002, 14, 1921-1929.

[69] J. LI. Tamarit, I. B. Rietveld, M. Barrio, R. Céolin, J. Molec. Struct., 2014, 1078, 3-9.

[70] M. Barrio, R. Levit, P. Lloveras , A. Aznar, Ph. Negrier , D. Mondieig , J. LI. Tamarit, Fluid Ph. Equilibria, 2018, 459, 219229.

[71] M. Barrio, H. Allouchi, J. LI. Tamarit, R. Céolin, L. BerthonCedille, I. B. Rietveld, Int. J. Pharm. 2019, 572, 118812.

[72] B.T. Goodman, W. V. Wilding, J.L. Oscarson, R. L. Rowley, J. Chem. Eng. Data 2004, 49, 1512-1514.

[73] R. M. Varushchenko, L. L. Pashchenko, A. I. Druzhinina, A. V. Abramenkov, A. A. Pimersin, J. Chem. Thermodynamics., 2001, 7, 733-744.

[74] L. M. Amzel, L. N. Becka, J. Phys. Chem. Solids., 1969, 30, 521538.

[75] Y. Huang, D. F. R. Gilson, I. S. Bulter, J. Chem. Soc. Faraday Trans., 1991, 87, 3835-3840.

[76] M. Romanini, Ph. Negrier, J.LI. Tamarit, S. Capaccioli, M. Barrio, L. C. Pardo, D. Mondieig, Phys. Rev. B, 2012, 85, 134201.

[77] A. B. Bazyleva, A. V. Blokhin, G. J. Kabo, A. G. Kabo, Y. U. Paulechka, J. Chem. Thermodynamics, 2005, 37, 643-657.

[78] M. A. Spackman, D. Jayatilaka, CrystEngCommun., 2009, 11, 1932.

[79] J. P. Amoureux, M. Foulon, Acta Crystallogr. B, 1987, 43, 470479.

[80] J. F. C. Silva,. M. T. S. Rosado, M. Jasiurkowska-Delaporte, M. R. Silva, M. F. M. Piedade, E. Dryzek, M. E. S. Eusébio, Cryst. Growth Des. 2019, 19, 6127-6135. 